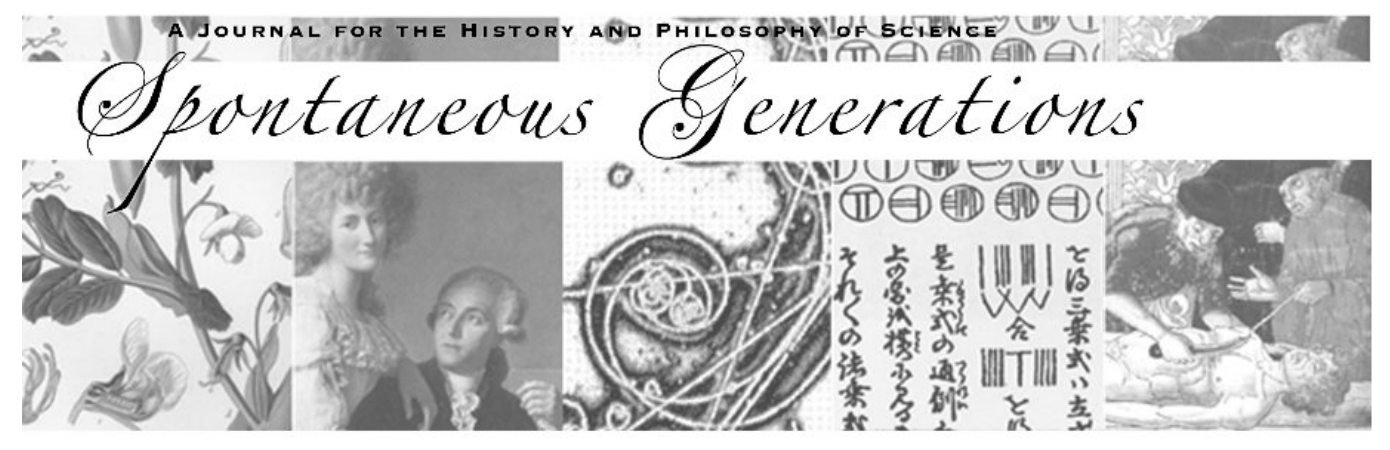

Exploring Epistemic Boundaries between Scientific and Popular Cultures

Author(s): Marina Levina

Source: Spontaneous Generations: A Journal for the History and Philosophy of Science, Vol. 3, No. 1 (2009) 105-112.

Published by: The University of Toronto

DOI: $10.4245 /$ sponge.v3i1.6569

EDITORIAL OFFICES

Institute for the History and Philosophy of Science and Technology

Room 316 Victoria College, 91 Charles Street West

Toronto, Ontario, Canada M5S $1 \mathrm{~K} 7$

hapsat.society@utoronto.ca

Published online at jps.library.utoronto.ca/index.php/SpontaneousGenerations ISSN 19130465

Founded in 2006, Spontaneous Generations is an online academic journal published by graduate students at the Institute for the History and Philosophy of Science and Technology, University of Toronto. There is no subscription or membership fee. Spontaneous Generations provides immediate open access to its content on the principle that making research freely available to the public supports a greater global exchange of knowledge. 


\title{
Exploring Epistemic Boundaries between Scientific and Popular Cultures*
}

\author{
Marina Levina ${ }^{\dagger}$
}

\begin{abstract}
Science studies have long been concerned with the complex interrelationship between scientific research and popular culture's interpretations and reconstructions of scientific findings (Kember 2003; Lancaster 2003; Penley 1997, among others). Disparities between the two are often presented as popular culture's misinterpretation or misrepresentation of scientific facts; however, in this essay I argue that a more theoretically lucrative approach understands these conflicts as complex social and cultural negotiations over epistemological boundaries between scientific and popular cultures. Understanding such differences is tremendously important in mediated societies where scientific research is mostly understood through its representation in the popular culture. In this paper, I examine what is at stake in popular representations of scientific research and how the popular culture is often seen as threatening to the epistemic boundaries of scientific culture. Using the recent controversy over The Oprah Winfrey Show's presentation of controversial medical practices as a case study, this essay examines how distinctions between scientific and popular ways of knowing are constructed, represented and managed. I argue that scientific knowledge should be viewed as a complex and often conflicted cultural discursive practice that signifies boundary negotiations between scientific and popular cultures.
\end{abstract}

This essay will first introduce the cultural debate that erupted over Oprah's use of celebrity experts and presentation of medically controversial practices. This case study will be illustrated through Newsweek magazine's article that first ignited the public debate on the issue and a sample of blog writings, which were selected because they most succinctly illustrate the epistemological tensions present in the debate. I present a theoretical distinction between the popularization of

*Received July 2009. Accepted November 2009.

$\dagger$ Marina Levina is a faculty member in the Media Studies Program at the University of California, Berkeley. Her research is in cultural studies of science, technology and medicine and critical media studies. She has published work on personal genomics, health information technology, and popular culture's engagement with scientific and medical research. She is a co-editor of Post-Global Network and Everyday Life (Peter Lang: 2010). 
science and alternative science and will argue that alternative science illustrates a tension between facts and opinions-a tension that was essential in the debate over The Oprah Winfrey Show. I argue that an important epistemological distinction between scientific and popular cultures can be best understood as a theoretical and cultural difference between knowledge and information. As a theoretical project, this essay will insist on opening up alternative science as a space-in-between scientific and popular culture: open to complex cultural and social epistemological negotiations.

In its June 8, 2009 issue, Newsweek magazine published a cover article titled "Crazy Talk: Oprah, Wacky Cures and You." The article was a cultural landmine because it was highly critical of The Oprah Winfrey Show, a nationally syndicated talk show that has been immensely popular and influential since its debut in 1986. A generation of viewers was raised with the show and its host, Oprah Winfrey, has become a powerful and influential cultural figure who has great influence over her audience's personal decisions and purchases. Oprah Book Club's selections routinely become national bestsellers and she has single-handedly launched the careers of numerous doctors, self-help gurus, and actors. The article decried Oprah's practice of offering celebrity guests a wildly popular and influential platform for advocating highly controversial and unproven medical practices. It argued that because of her immense popularity and influence, Oprah should be much more careful in choosing which medical practices she appears to endorse. The authors start by describing one such guest:

In January, Oprah Winfrey invited Suzanne Somers [a popular actress best known for her role on popular TV show Three's Company] on her show to share her unusual secrets to staying young. Each morning, the 62-year-old actress and self-help author rubs a potent estrogen cream into the skin on her arm. She smears progesterone on her other arm two weeks a month. And once a day, she uses a syringe to inject estrogen directly into her vagina. The idea is to use these unregulated "bio-identical" hormones to restore her levels back to what they were when she was in her $30 \mathrm{~s}$, thus fooling her body into thinking she's a younger woman. According to Somers, the hormones, which are synthesized from plants instead of the usual mare's urine are all natural and, unlike conventional hormones, virtually risk-free She swallows 60 vitamins and other preparations every day. Somers makes astounding claims about the ability of hormones to treat almost anything that ails the female body. She believes they block 
disease and will double her life span. "I know I look like some kind of freak and fanatic," she said. "But I want to be there until I'm 110, and I'm going to do what I have to do to get there." (Kosova and Wingret 2009, 55)

According to the article, the main problem with these kinds of appearances is not necessarily a simple presentation of extreme and questionable medical practices, but rather Oprah's apparent endorsement of these scientific unproven claims. The article continues:

That was apparently good enough for Oprah. "Many people write Suzanne off as a quackadoo," she said. "But she just might be a pioneer." Oprah acknowledged that Somers's claims "have been met with relentless criticism" from doctors. Several times during the show she gave physicians an opportunity to dispute what Somers was saying. But it wasn't quite a fair fight. The doctors who raised these concerns were seated down in the audience and had to wait to be called on. Somers sat onstage next to Oprah, who defended her from attack. "Suzanne swears by bioidenticals and refuses to keep quiet. She'll take on anyone, including any doctor who questions her." (55)

The Newsweek story recounted several such episodes from The Oprah Winfrey Show, including numerous appearances by actress Jenny McCarthy who is convinced that vaccinations caused her son's autism and has since embarked on an educational crusade urging parents to seriously consider delaying vaccinations. The Newsweek story set off a maelstrom in the blogosphere. Most commentators agreed with Newsweek's assessment that Oprah behaved irresponsibly in presenting, and seemingly endorsing, scientifically questionable information to her viewers. On June 1, 2009, in the influential blog, Science-Based Medicine, Dr. David Gorsky argued in a widely quoted post that the Newsweek article hints at a larger problem he describes as the "Oprah-fication" of medicine:

Naturally, Oprah doesn't see it that way and likely no one could ever convince her of the malign effect she has on the national zeitgeist with respect to science and medicine, but that's exactly what she does. Consequently, whether fair or unfair, she represents the perfect face to put on the problem that we supporters of science-based medicine face when trying to get the message out to the average reader about unscientific medical practices, and that's why I am referring to 
the pervasiveness of pseudoscience infiltrating medicine as the "Oprah-fication" of medicine.

In a sense Dr. Gorski describes the problem as an epistemic one-what science "knows" and what popular culture presents as scientific knowledge are often at odds. On June 8, 2009 Peter A. Lipson, M.D. explicitly stated in his blog White Coat Underground that The Oprah Winfrey Show underscores the different epistemic standards between science and popular culture:

Many debates have two equally-valid viewpoints, but this isn't so in science and medicine. A treatment is either proven to work or proven not to work. Occasionally, plausible ideas are sitting somewhere in between hoping for evidence to push them one way or the other. Notice the word "evidence"-not waiting for the verdict of a TV talk show, not waiting for a news anchor's opinion, but waiting for evidence. That's why there is no such thing as "alternative medicine"; there is only that which has been shown effective, and that which has not.

According to the commentary, this is the source of tension between scientific and popular culture. The scientific community has well-established epistemological criteria for determining what counts as knowledge. In contrast, popular culture is often focused on presentation of scientific information, often through celebrity spokespeople, without much regard to the criteria of scientific community. Therefore, rather often, popular culture constructs alternative scientific facts and information. As Dr. John Grohol put it on The Huffington Post blog on June 9, 2009, "in science, there are varying degrees of standards and quality, and a process called "peer-review" that ostensibly seeks to weed out junk or poor science from the high quality, objective science. It's the usual process researchers use to communicate with one another about these kinds of controversies. Short-circuiting the process through celebrities like Oprah, McCarthy and Somers ensures that only one side gets heard."

These statements seem to be based on the traditional model of popularization which views popularization as external to the knowledge production and validation practices employed by scientists (Miller 2009). However, this model has been challenged by empirical research, which points out more complex relations between science and its popularization in the general media (Dornan 1989; Locke 1999). Stephen Hilgartner argues that the dominant view of popularization is based on an idealized notion of pure scientific knowledge. He writes, "The dominant view [is] used in rhetorical 'boundary work' to demarcate 'genuine' from 
'popularized' knowledge. A concept of purity requires one [view] of contamination, and the notion of popularization shores up an idealized view of genuine, objective, scientific-certified knowledge" (1990, 520). He further argues that while the dominant view of popularization assumes the existence of an epistemic gold standard, distinctions between "pure" and "popular" science depend on the context in which they are invoked and are hard to sustain. Hilgartner posits that these distinctions are often based in cultural and political practices and that therefore it is important to understand how labels such as "genuine science," "popularization," and "distortion" are deployed, by whom, when, and to what purposes.

However, I argue that these statements are not only demonstrative of a controversy over the nature of scientific knowledge and its deployment, but also point to the limitations of traditional scientific popularization models when discussing the relationship between scientific and popular cultures. The distinction between facts and opinions that guides the Newsweek article and the subsequent blog posts is based on an understanding of science popularization that positions science outside of the public and relegates knowledge formed outside of scientific boundaries to the sphere of opinions and pseudo-science (Bensaude-Vincent, 2001). Here I juxtapose popularization to alternative science. The former is a disciplinary attempt to negotiate epistemological boundaries between scientific and popular cultures, whereas the later introduces an epistemological cross-space between the two cultures. If, as Gieryn (1999) argues, "'science' becomes a space on maps of culture bounded off from other territories, labeled with landmarks showing travelers how it is different from regions of common sense, politics, or mysticism" (x), then alternative science represents a space outside science.

A more fruitful discussion would engage with The Oprah Winfrey Show as an example of alternative science-a space that opens a debate and questions the limits of reified scientific knowledge and expertise. Whether or not the information dispensed by Oprah is "accurate" according to current scientific standards is irrelevant to the kind of public debate needed about alternative science. What matters more is how the alternative science can be deployed to investigate the epistemological boundaries between the scientific establishment and the public. After all The Oprah Winfrey Show can serve as a powerful alternative science platform that issues a "word of warning for the medical establishment: 'We have the right to demand a better quality of life for ourselves,' Oprah said. 'And that's what doctors have got to learn to start respecting'" (Kosova and Wingret 2009, 57). This is much more than just a populist grandstanding against the medical establishment-it is also a part of the tension between scientific and popular cultures. If one considers these episodes of The 
Oprah Winfrey Show as a space for alternative science, then it makes an argument that the production of knowledge or facts is not reserved for the scientific realm. In the realm of alternative science, doctors and other scientific experts are no longer principal actors who get to set the agenda, define facts, and delineate what constitutes a proper discussion. I agree here with Miller (2009) who argues that scientific participation in popular media means that scientists have to accept that they are no longer the only actors who get to set standards for what is presented. But even more importantly, in the space of alternative science the division between fact and opinion is complicated at best. Moreover, a traditional understanding of knowledge and facts as generated by experts has been uniquely challenged by the rise of information technologies and the wide access to all parts of popular culture and media. As Lewenstein (1995) pointed out, the effects of information technologies on scientific inquiry has been largely unexamined. Fourteen years later, we are almost no closer to understanding how the rise in access to various facets of information technology will affect the public's relationship to the scientific culture.

Therefore, to condemn The Oprah Winfrey Show as irresponsible schlock or as misrepresentation of science, as the Newsweek article and subsequent blog posts do, is to miss the point of what the show represents about the public's relationship to scientific knowledge. Susan Somers, Jenny McCarthy, and Oprah herself might be famous, but they represent a common frustration with the "black box" of science and the facts it generates. Whereas alternative science creates a space where facts and opinions, both scientific and the popular can co-exist in meaningful ways, the traditional discourse of science popularization promotes an epistemological division between scientific and popular cultures, juxtaposes fact and opinion, and condemns public opinion as pseudo-knowledge.

I argue that epistemological boundaries between scientific and popular culture can be best understood through a theoretical distinction between knowledge and information. Whereas the scientific community is dedicated to producing verifiable knowledge, the popular culture specializes in generating an infinite quantity of information. In her response to the Newsweek article on Entertainment Tonight on June 4, 2009 Oprah referred to this very thing: "for 23 years, my show has presented thousands of topics that reflect the human experience, including doctors' medical advice and personal health stories that have prompted conversations between our audience members and their health care providers. I trust the viewers, and I know that they are smart and discerning enough to seek out medical opinions to determine what may be best for them." On Oprah's website forum boards, viewers repeated that they appreciate the 
information presented on the show, while still relegating the authority of knowledge to their health care provider. These and other conflicts between scientific and popular cultures represent an incongruity in epistemological practices. Knowledge is not information and information is not knowledge. One relies on a carefully defined and policed set of rules, regulations and practices, whereas the other produces and reproduces itself in the wider public sphere. Knowledge is stabilized in scientific institutions, while information is continuously changing and continuously in flux. Without institutions to give it form, information flows through the network-difficult to fix, difficult to manage, difficult to control. Whereas knowledge generates meaning, one could argue that the more information there is, the less meaning there is (Terranova 2004). While the lack of fixed meaning can be problematic, I argue here that alternative science can offer a space where the tension between facts and opinions or knowledge and information can be put forth in the public sphere and hopefully resolved. This is an important contribution of The Oprah Winfrey Show and therefore to dismiss it as a failed experiment in science popularization is to miss opportunities that it offers. And as the general public acquires information with which to dispute scientists' knowledge, science studies needs to do the theoretical work required to understand the consequences of the popular culture's expertise in distributing information while never reifying it as knowledge.

\author{
MARINA LEVINA, PhD \\ Media Studies Program \\ University of California, Berkeley \\ 301 Campbell Hall \# 2922 \\ Berkeley, CA 94720 \\ mlevina@berkeley.edu
}

\title{
REFERENCES
}

Gieryn, Thomas. 1999. Cultural boundaries of science: credibility on the line. Chicago: University of Chicago Press.

Hilgartner, Stephen. 1990. The Dominant View of Popularization: Conceptual Problems, Political Uses. Social Studies of Science 20(3): 519-39.

Kember, Sarah. 2003. Cyberfeminism and artificial life. New York: Routledge.

Kosova, Weston, and Pat Wingert.. "Crazy Talk: Oprah, Wacky Cures, and You." Newsweek, June 8, 2009.

Lancaster, Roger. 2003. The trouble with nature: Sex in science and popular culture. Berkeley: University of California Press.

Lewenstein, B.V. 1995. From Fax to Facts: Communication in the Cold Fusion Saga. Social Studies of Science 25(3): 403-36. 
Locke, Simon. 1999. Golem science and the public understanding of science: From deficit to dilemma. Public Understanding of Science 8(2): 75-92.

Miller, Boaz. 2009. What Does It Mean that PRIMES is in P?: Popularization and Distortion Revisited. Social Studies of Science 39(2): 257-288.

Penley, Constance. 1997. NASA/Trek. London: Verso.

Terranova, Tiziana. 2004. Network culture: politics for the information age. London: Pluto Press. 